\title{
A comparison study of the Romanian occupational safety and health strategy with other European countries' strategy
}

\author{
Nicoleta Paula $\mathrm{NEAG}^{1, *}$ \\ ${ }^{1}$ Politehnica University of Timisoara, Faculty of Management in Production and Transportation, 14 \\ Remus street, 300191 Timisoara, Romania
}

\begin{abstract}
The European Union Strategic Framework on Occupational Health and Safety at Work 2014 - 2020 has pushed the Member States to review their national strategies. Thus, national strategies have customized, the European vision to the national culture and specifics, considering the European framework that acts as a common guide and reference. The 2018 Report on occupational safety and health strategies in Europe, do not include the Romanian strategy. Based on the national strategy last version (2018), the paper will present and debate a comparative analysis between the Romanian OHS strategy and the other Member State strategy. This research approach is meant to identify, and underline Romania's efforts made in the field of OHS, but also the gaps and missing aspects of the related strategy in comparison with the other countries.
\end{abstract}

\section{INTRODUCTION}

The European Union Strategic Framework on Health and Safety at Work for the period 2014 - 2020 has pushed the member states to up-date their national strategies in close consultation with relevant stakeholders including the social partners. Furthermore, national strategies were pushed to customize the European vision and adapt it to the national culture and specifics, considering the European framework that acts as a common guide and reference. The last report on the OSH legislative harmonization between the Member States has been published in 2018 [1] but Romanian OSH strategy was not included in the analysis.

Romania has adopted several versions of the National Strategy for Health and Safety at Work and the last one is related to the 2018 - 2020 period (Decision no. 191/2018 of 4 April 2018). Based on this document and the implementation plan the paper will present and debate a comparative analysis between the Romanian OHS strategy and the other Member State strategy, taking into consideration the 2018 Report done at the European level [1]. This research approach is meant to identify, and underline Romania's efforts made in the field of OHS, but also the gaps and missing aspects of the related strategy in comparison with the other countries.

\footnotetext{
* Corresponding author: nicoleta.neag@student.upt.ro
} 


\section{The state OSH strategy in the European Union}

EU Strategic Framework on Health and Safety at Work 2014-2020 (the background of the comparative study) was elaborated in the perspective of a better cooperation between the 27 Member States, to serve as guideline for the elaboration process of the national strategies and to encourage the adoption of the related OSH directives; The OSH EU framework set minimum requirements to improve the working environment in order to protect workers' health and safety. EU action on OSH has been pursued over the years within a strategic policy framework that includes two key strategic objectives:

- Consolidate and extend the information network on national OSH strategies;

- Enhance information tools for evidence-based policy-making, including monitoring the implementation of the EU Directives and norms in the OSH field.

In this context, the last comparison study supported by the specialists of the European Agency for Safety and Health at Work was meant to characterized and report the Member States national OSH strategies in the actual context [1]. With the help of contact points responsible for national strategies elaboration, created under the strategic framework, EU OSHA has collected information to develop the comparative study reflecting the state of the European strategy implementation. The objectives of the comparative study on OSH national strategies were: (1) to collect data across European Union (EU) Member States to allow a comparison of national OSH systems; (2) to identify the extent to which the EU Strategic Framework has influenced national strategies, and (3) to provide an overview of approaches and their common content and/or structure [1].

The report has included the national OSH strategies of 25 Member States: Austria, Belgium, Bulgaria, Cyprus, Czech Republic, Denmark, Estonia, Finland, France, Germany, Greece, Hungary, Italy, Ireland, Latvia, Lithuania, Malta, Netherlands, Poland, Portugal, Slovakia, Slovenia, Spain, Sweden and the United Kingdom [1]. The information on the Romanian OSH strategy are missing from the Report and for this reason the present article will present the state and the strategic direction that should be taken in the nearest future, at the national level, having in mind the European framework of OSH. For the moment of the 2018 Report elaboration, the Romanian national OSH strategy has not been incorporated because no English translation was available.

According to the Report results, in general, new OSH strategies in the European countries are less optimistic and more realistic compared to former strategies; optimistic goal-setting in former strategies have been replaced by specifically defined actions, including monitoring, reporting and evaluation measures. These better-defined goals and measures in terms of their achievability.

The EU strategic framework had a very clear influence on national OSH strategies. The European strategy is perceived as having a valuable contribution in delivering a general framework for OSH and, also, it offers opportunities for better implementation of OSH principles, supporting a better collaboration between OSH stakeholders. Their focus is now to work systematically on diminishing or eliminate the weaknesses of a national system, and they play a central role in national debates and activities on OSH. A proper assessment of national OSH strategies needs to consider the policy programs in related areas that might have strong influence on health and safety at work (such as on rehabilitation, return to work, public health programs, social policy measures etc.) [1].

However, the 2018 Report on OSH national strategy has clearer underlined that any expectation that strategies might be tools to significantly rearrange the basic infrastructures of OSH has been proved as being regarded as an overestimation of their impact. Their value lies in collaborative actions that can address the major weaknesses. Furthermore, the comparison study of the national strategies related to the 26 Member States has recognized the main challenges in the actual context of the OSH [1]: 
- Improving the implementation record of Member States, by enhancing the capacity of micro and small enterprises to put in place effective and efficient risk prevention measures;

- Improving the prevention of work-related diseases by tackling existing, new and emerging risks;

- Tackling demographic change, a sustainable working life and active and healthy ageing.

The Commission proposes a range of actions to be implemented or developed in close collaboration with Member States, social partners and other stakeholders, grouped under seven key strategic objectives. Each national focal point manages its own tripartite network comprising of government bodies and representatives from worker and employer organizations and they have been proved as effective and efficient organizations for promoting the OSH campaigns, best practices, as well as legislations, norms and standards. Furthermore, the 2018 Report shows that legislation has proven its value in providing the EU with a common body of definitions, standards, methods and preventive tools in the $\mathrm{OSH}$ area. An EU-wide OSH legislative framework is crucial to ensure high level of protection for workers and to create a level playing-field for all organizations (companies, public bodies, of different size or economic sector, and from different location). Since now, there have been collected best practices from different European countries' organizations showing that fulfilling legal obligations and enforcement measures taken by external controlling bodies (e.g. the case of OSH audit and including the labor inspection bodies) remain key drivers of the OSH management [1].

\section{The Romanian OSH Strategy (2018 - 2020)}

In Romanian, the OSH system might be characterized by a comprehensive legislative framework that fully transposed the EU legislation in the area and an adequate institutional framework aligned to the Community requirements in the field. The Law No. 319 of 2006, known as the Health and Safety at Work Law, constitutes a benchmark in terms of the safety and health approach in Romania and the actual legislation, norms and regulations support significant improvements in OSH field towards well-being at work and a higher quality of the work and life, in general. The Focal Point for Romania of the European Agency for Safety and Health at Work is one of the key organizations as regards the awareness raising actions on $\mathrm{OSH}$ at the economy and societal level. It constitutes the interface between the Romanian major OSH stakeholders (including social partners) and the European Agency for Safety and Health at Work, thus ensuring a two-way dissemination of relevant information.

The National Strategy on Health and Safety at Work has been developed first in 2014, for the period of 2014 - 2020, and then up-dated in 2018 (the Ministry of Labor and Social Justice is the competent authority in the OSH field at the national level). OSH strategy has considered and careful approach the future EU challenges as the occupational diseases, new and emerging risks, demographic changes (ageing workforce, migration), the legal framework (valid in 2018), and pay a special attention to the improved of the statistical tools and report methodologies on OSH. Despite the significant reduction in accidents and better prevention, health and safety at work still needs further improvement, according to the available statistic data in 2018 [2-6]. The general objectives of the OSH Romanian strategy are:

- More efficient implementation a health and safety in work legislation of micro and small enterprises. This requires simplifying legislation where appropriate and providing tailored guidance and support to micro and small enterprises to facilitate risk assessment (also demonstrated by the research of [7-9]); 
- Protection of workers, health and safety in all workplaces regardless of size. Major efforts were made to prevent occupational diseases and new or emerging risks (underlined by the experimental researches related to [10-11]);

- Improving the prevention of work-related diseases by tackling existing, new and emerging risks (as proofed also by the researches of $[11,12]$ );

- Improving health and safety for aging work force is necessary for a sustainable working life and active, healthy ageing (in the conditions of the extension of working life) (proofed by the demographic research of [10-12]).

With these observations and general characterization of the Romanian state and strategy on OSH, we shall next present a comparison of the situation with those included in the European Report on OSH strategies [1].

\section{Romania OSH strategy in comparison with the situation of the other Member States strategies}

As there have been mention previous in this article, the OSH strategy for Romania was not included in the 2018 Report of the European Agency for Safety and Health at Work. The analysis of the National Strategy on Health and Safety at Work for 2018 - 2020 (Decision no. 191/2018) [13] has provided information for the integration and the comparison of the Romanian approach on OSH with the other Member States of the European Union. The first result of the analysis has underlined how the three Challenges identified in the 2018 Report [1] are faced and the results are synthesis in Table 1. As can be seen, Romanian OSH strategy includes prevention measures for all three Challenges.

The second step of the analysis has been focused on the comparative analysis of how the Seven Key Objectives debated in [1] are address by the Romanian OSH strategy [13]. The synthesis of this analysis is shown in Table 2. Most of the European Union OSH strategy has been integrated in the Romanian OSH strategy, except the last one for which there are no measures related to the practical implementation. This could be the main cause of the missing data about Romania in the 2018 Report on OSH strategies, even though Romanian OHS stakeholders are very well described (together with their tasks, actions and responsibilities) in the strategy [13]. In order to increase transparency and the European collaboration of the Romanian stakeholders there should be considered a higher implication of them for the international level, simultaneously with demonstrating their efforts in addressing $\mathrm{OSH}$ activities (measures implementations, best practices, campaigns, education and training in the field, legislative efforts, transparency in statistical data collection and providing etc.) and increase their engage with OSH international organizations (not only at the European level).

In the third step, there has been developed an analysis of the topics mentioned in the EU Strategic Framework (in Second Challenge [1]) based on their inclusion and concern by the national OSH strategies, including the Romanian OSH strategy [13]. The comparative study results are presented in Table 3. As it can be observed, Romanian OSH strategy addresses all the topics related to the Second Challenge [1] but the study of the official document [13] do not show explicit measures, but much general one; referring to the topics $a$ and $b$ in Table 4, the analysis has proof that there is no correlation of the occupation diseases statistics with the measure plan, despite the fact that specific OSH stakeholders are mentioned having responsibilities in this field. Regarding the $d$ topic, there were expected more measures and the existing of an explicit plan for the OSH problems in the case of information technology workplaces, considering the last years development of the sector (supported by the research of [14-18]). In the case of the topic related to stress and ergonomic risks could be better addressed if the national efforts of the specialists could be joint in a national ergonomics association (fragmentation of research and their applications 
is the practice) and similar, in the case of topic $\mathrm{g}$, there is a limitation of medical services predominantly to health assessment actions, to the detriment of health prevention.

Table 1. How Member States OSH strategies face the challenges considered in [1].

\begin{tabular}{|c|c|c|c|}
\hline Country & $\begin{array}{c}\text { Challenge 1: } \\
\text { Improving } \\
\text { implementation record } \\
\text { (particularly by } \\
\text { supporting small and } \\
\text { medium size } \\
\text { enterprises and micro } \\
\text { enterprises) }\end{array}$ & $\begin{array}{l}\text { Challenge 2: Improving } \\
\text { prevention of work- } \\
\text { related diseases by } \\
\text { tackling existing, new and } \\
\text { emerging risks }\end{array}$ & $\begin{array}{l}\text { Challenge 3: Tackling } \\
\text { demographic change }\end{array}$ \\
\hline Austria & $\bullet$ & $\bullet$ & $\bullet$ \\
\hline Belgium & $\bullet$ & $\bullet$ & $\bullet$ \\
\hline Bulgaria & $\bullet$ & $\bullet$ & $\bullet$ \\
\hline Cyprus & $\bullet$ & $\bullet$ & $\bullet$ \\
\hline $\begin{array}{c}\text { Czech } \\
\text { Republic }\end{array}$ & $\bullet$ & $\bullet$ & $\bullet$ \\
\hline Denmark & $\bullet$ & $\bullet$ & $\mathbf{x}$ \\
\hline Estonia & $\bullet$ & $\bullet$ & $\bullet$ \\
\hline Finland & $\bullet$ & $\bullet$ & $\bullet$ \\
\hline France & $\bullet$ & $\bullet$ & $\bullet$ \\
\hline Germany & $\bullet$ & $\bullet$ & $\bullet$ \\
\hline Greece & $\bullet$ & $\bullet$ & $\bullet$ \\
\hline Hungary & $\bullet$ & $\bullet$ & $\bullet$ \\
\hline Italy & $\bullet$ & $\bullet$ & $\bullet$ \\
\hline Ireland & $\bullet$ & $\bullet$ & $\bullet$ \\
\hline Latvia & $\bullet$ & $\bullet$ & $x$ \\
\hline Lithuania & $\bullet$ & $\bullet$ & $\bullet$ \\
\hline Malta & $\bullet$ & $\bullet$ & $x$ \\
\hline Netherlands & $\bullet$ & $\bullet$ & $\bullet$ \\
\hline Poland & $\bullet$ & $\bullet$ & $\bullet$ \\
\hline Portugal & $\bullet$ & $\bullet$ & $\bullet$ \\
\hline Romania & $\bullet$ & $\bullet$ & $\bullet$ \\
\hline Slovakia & $\bullet$ & $\bullet$ & $\bullet$ \\
\hline Slovenia & $\bullet$ & $\bullet$ & $\bullet$ \\
\hline Spain & $\bullet$ & $\bullet$ & $\bullet$ \\
\hline Sweden & $\bullet$ & $\bullet$ & $\bullet$ \\
\hline $\begin{array}{c}\text { United } \\
\text { Kingdom }\end{array}$ & $\bullet$ & $\bullet$ & $x$ \\
\hline
\end{tabular}

Table 2. Comparative analysis on the Seven Key Objectives of [1] with Romanian OSH strategy [13]

\section{Objectives}

1. Further consolidate national strategies

2. Facilitate compliance with OSH legislation, particularly by micro and small enterprises

3. Better enforcement of OSH legislation by
Observations and debates related to the national OSH strategies of the Member States

Implicitly all countries by preparing an updated strategy. Romania has achieved this objective by the last 2018 up-date of the OSH strategy.

Most countries mention adaptation and implementation of legislation as important step, many also identify SME as a challenge. Romania OSH strategy includes specific measures for this objective (objective 1 and 2 of the national strategy)

Not explicitly but indirectly approached in all countries. Romanian OSH strategy has been up-date in 2018 and the European OSH 


\begin{tabular}{|c|c|c|}
\hline & Member States & $\begin{array}{l}\text { legislation has been considered (a lack of implementation or practical } \\
\text { transfer are still needed) }\end{array}$ \\
\hline 4. & $\begin{array}{l}\text { Simplifying existing } \\
\text { legislation }\end{array}$ & $\begin{array}{l}\text { - The word 'simplify' is used by Cyprus, Denmark, France, } \\
\text { Finland, Greece, Ireland, Malta, Slovakia, Sweden and United } \\
\text { Kingdom; } \\
\text { - Belgium: clear legislation that is easy to apply; } \\
\text { - Slovenia mentions reduction of administrative burdens; } \\
\text { - Romania aims to simplify the administrative procedures } \\
\text { regarding signaling and the declaration of occupational diseases }\end{array}$ \\
\hline 5. & $\begin{array}{l}\text { Address the ageing of } \\
\text { the workforce, } \\
\text { emerging new risks, } \\
\text { prevention of work- } \\
\text { related and } \\
\text { occupational diseases }\end{array}$ & $\begin{array}{l}\text { - The ageing of workforce is not tackled by all countries. } \\
\text { - The prevention of risks and injuries is an objective in every } \\
\text { country, including Romania (objective } 4 \text { of the national } \\
\text { strategy) }\end{array}$ \\
\hline 6. & $\begin{array}{l}\text { Improve statistical } \\
\text { data collection and } \\
\text { develop the } \\
\text { information base }\end{array}$ & $\begin{array}{l}\text { Particularly mentioned in Belgium, Bulgaria, Cyprus, Denmark, France, } \\
\text { Hungary, Italy, Netherlands and Slovenia (a reform of OSH statistics is } \\
\text { envisaged), Greece (occupational accidents and diseases), Portugal and } \\
\text { United Kingdom (cost aspect), and Romania (related to occupational } \\
\text { diseases, mentioned by objective } 5 \text { of the national strategy) }\end{array}$ \\
\hline & $\begin{array}{l}\text { Better coordinate EU } \\
\text { and international } \\
\text { efforts to address } \\
\text { OSH and engage with } \\
\text { international } \\
\text { organizations }\end{array}$ & $\begin{array}{l}\text { Particularly mentioned by Austria, Bulgaria, Cyprus, Czech } \\
\text { Republic, Finland, Hungary, Poland, Portugal, Slovakia and Sweden }\end{array}$ \\
\hline
\end{tabular}

Table 3. Analysis of the topics mentioned in the EU Strategic Framework (in Second Challenge) based on their inclusion and concern by the national OSH strategies

\begin{tabular}{|c|c|}
\hline \multicolumn{1}{|c|}{ Topics } & \multicolumn{1}{c|}{ Countries } \\
\hline $\begin{array}{l}\text { a. Cancer causing occupational } \\
\text { exposure, fatalities associated } \\
\text { with chemical substances }\end{array}$ & $\begin{array}{l}\text { Belgium, Cyprus, Denmark, France, Finland, Hungary, Italy, } \\
\text { Ireland, Netherlands, Poland, Portugal, Romania, Slovenia }\end{array}$ \\
\hline $\begin{array}{l}\text { b.Diseases caused by asbestos, } \\
\text { lung diseases, skin diseases, } \\
\text { asthma and other chronic } \\
\text { conditions }\end{array}$ & $\begin{array}{l}\text { All countries tackle these specifically or under the term } \\
\text { occupational diseases }\end{array}$ \\
\hline $\begin{array}{l}\text { c. New technologies and } \\
\text { innovations in work } \\
\text { organization }\end{array}$ & $\begin{array}{l}\text { Explicitly mentioned by Belgium, Bulgaria, France, Germany, } \\
\text { Greece, Hungary, Italy (work organization), Ireland, Latvia } \\
\text { (non-standard forms of employment), Lithuania, Romania } \\
\text { (new technologies and non-standard forms of employment), } \\
\text { Slovakia, Slovenia, Spain and Sweden }\end{array}$ \\
\hline $\begin{array}{l}\text { d.Nanomaterials, and green } \\
\text { biotechnologies and } \\
\text { technologies. Information } \\
\text { technology developments, } \\
\text { e.g. constant connectivity } \\
\text { Republic, Denmark, France, Germany, Poland, Portugal, } \\
\text { Slovenia and Spain } \\
\text { Green technologies: Sweden (but referring to agriculture) } \\
\text { Information technology: Implicitly all (weak } \\
\text { representation in the Romanian OSH strategy, only } \\
\text { discreet referring) }\end{array}$ \\
\hline $\begin{array}{l}\text { e. Workforce diversity, atypical } \\
\text { contractual arrangements and } \\
\text { work patterns, a higher job } \\
\text { turnover associated with } \\
\text { shorter job assignments, } \\
\text { especially for younger } \\
\text { workers }\end{array}$ & $\begin{array}{l}\text { Most of the countries tackle these topics either specifically or } \\
\text { in general under terms like emerging risks or changes in the } \\
\text { workforce, Romania (changes in the labor market) }\end{array}$ \\
\hline
\end{tabular}




\begin{tabular}{|l|l|}
\hline $\begin{array}{l}\text { f. Stress, ergonomic risks } \\
\text { (repetitive movements or } \\
\text { tiring or painful positions and }\end{array}$ & $\begin{array}{l}\text { Stress is explicitly mentioned by Austria, Belgium, Bulgaria, } \\
\text { Cyprus, Czech Republic, Finland, Germany, Greece, Italy, } \\
\text { lifting, carrying or moving } \\
\text { loads daily) }\end{array}$ \\
$\begin{array}{l}\text { Ireland, Latvia, Lithuania (psychosocial risks), Poland, } \\
\text { Slovakia, Slovenia, Spain, Sweden and United Kingdom. } \\
\text { Ergonomics is mentioned by Austria, Czech Republic, Finland, } \\
\text { Germany, Hungary, Latvia, Lithuania and Poland (weak } \\
\text { represented in Romania). In addition, musculoskeletal } \\
\text { disorders are often mentioned under occupational diseases }\end{array}$ \\
\hline $\begin{array}{l}\text { g.Impact of changes in work } \\
\text { organization in terms of } \\
\text { physical and mental health }\end{array}$ & $\begin{array}{l}\text { Most of the countries tackle these topics either specifically or } \\
\text { in general under different terms. }\end{array}$ \\
\hline
\end{tabular}

\section{Conclusions}

The comparative analysis of the 2018 Report on OSH strategies [1] and the national OSH strategy for Romania has identified the substantial efforts that has been made in the field, to harmonize, customize the European legislation in the national context. In addition, the OSH European framework has been proved as a valuable tool for better defining the OSH stakeholders (including the social partners as employees' representatives for OSH problems) and their tasks. The up-date Romanian OSH strategy of 2018 has a lack in financial support, and this will negatively affect the implementation process.

Despite the efforts of harmonization and definition of a functional national framework of OSH, is affected by non-integration of the national OSH stakeholder:

- Lack of collaboration of the internal major OSH stakeholders as the Ministry of Labor and Social Justice (formerly named Ministry of Labor, Family and Social Protection), the Ministry of Health, national and territorial entities of labor inspection and the main $\mathrm{OSH}$ research institutes (The National Research and Development Institute of Occupational Safety "Alexandru Darabont", INCDPM and The National Institute for Research and Development in Environmental Protection, INSEMEX [14]). This have conducted to the elaboration of a less explicit and detail set of measures for the strategy implementation;

- Lack of international collaboration and implication of the Romanian OSH stakeholders for amplifying their effort in the field of occupational risk management and well-being, but also, for increasing the visibility of the national OSH strategy implementation together with the associated measures plan;

- Lack of specific measures in creating functional OSH hubs for consulting and trainings in the field but based on a scientific interdisciplinary approach in the field (with the implication of all actors, stakeholders).

Future researches should be focus on a detailed (critical) analysis of the Romanian OSH strategy and the actual state of its implementation. A SWOT analysis of the situation could show and support the strategic direction to be followed.

\section{References}

1. E. Schmitz-Felten, L. Lieck, National Strategies in the field of Occupational Safety and Health in the EU, Report published by the European Agency for Safety and Health at Work, EU-OSHA, (2018), available at: https://osha.europa.eu/en/safety-and-health-legislation/osh-strategies (Access on March 3, 2019)

2. EU-OSH, European opinion poll on occupational safety and health (2013), available at: https://osha.europa.eu/ro/surveys-and-statistics-osh/european-opinion-polls-safety-and-healthwork/european-opinion-poll-occupational-safety-and-health-2013 (Access on March 3, 2019) 
3. Work Inspection Romania, The work accidents statistics 2013 - 2017, available at: https://www.inspectiamuncii.ro/statistici-accidente-de-munca (Access on March 3, 2019)

4. L. Ivascu, L. I. Cioca, Occupational Accidents Assessment by Field of Activity and Investigation Model for Prevention and Control. Safety, 5(1), 12 (2019)

5. N. Băncilă-Afrim, R. I. Moraru, L. I. Cioca, G. B. Babut, Accidents at work among industrial presses operators: analysis of statistics in North-Western Region of Romania, Qual.-Access Success, 20 (2019)

6. M. Simionescu, The Impact of Work Accidents on the Sickness/Health Care Expenses in Romania. A Panel Data Approach, Economic Studies Journal, 2, 29-40 (2016)

7. Antonov, A. E., Buica, G., Darabont, D. C., Beiu, C. (2017). Tools for Preventing Occupational Risks for SMEs - A Prerequisite for Improving Productivity, Enviro Eng Manag J, 16(6) (2017)

8. C. Bejinariu, C., D. C. Darabont, E. R. Baciu, I. Ionita, M. A. B. Sava, C. Baciu, Considerations on the Method for Self-Assessment of Safety at Work, Enviro Eng Manag J, 16(6) (2017)

9. K. Jørgensen, Integration of safety in management tasks in onshore transport SME's, In 8th International Conference on Working on Safety: Smart Prevention for Sustainable Safety, WOS2015 Scientific Committee (2015)

10. G. B.Babut, R. I. Moraru, Occupational risk assessment: imperatives for process improvement, Quality-Access to Success, 19(166), 133-144 (2018)

11. D. C.Darabont, R. I. Moraru, A. E. Antonov, C. Bejinariu,. Managing new and emerging risks in the context of ISO 45001 standard, Qual.-Access Success, 18(S1), 11 (2017)

12. A. Gaureanu, A. Draghici, H. Weinschrott, Increasing the quality of occupational safety and health implementations through awareness training for those involved in implementing the Safety Observation Report, Qual.-Access Success, 20(S1), 141 (2019)

13. L. A. Sala, Demographic Ageing and Labor Market Shortages - Case of Romania, Economic and Social Development: Book of Proceedings, 283-292 (2018)

14. Romanian Government, Decision no. 191/ 4 April 2018, available at: http://www.mmuncii.ro/j33/images/Documente/Legislatie/HG191-2018.pdf (Access on March 8, 2019)

15. O. Stratulat, G. Ciobanu, Romanian IT\&C Industry Development in the Context of Development of the Digital Economy, Quality-Access to Success, 17 (2016)

16. S. Vaduva, D. S. Neagoie, Surviving and thriving in the global economic crisis: The journey and potential of the Romanian IT\&C sector, Procedia-Social and Behavioral Sciences, 221, 203-210 (2016)

17. G. Cazabat, D. M. Paraschiv, A. C. Călin, O. C. Popovici, A contemporaneous statistical note on e-commerce adoption in Romania Based SMEs, Amfiteatru Economic, 21(50), 177-193, (2019)

18. M. Zaharia, A. Balacescu, IT\&C used by Individuals and Economic Development in Romania Application of Cointegration and Vector Error Correction Model, Journal of Applied Computer Science \& Mathematics, 12(1) (2018) 